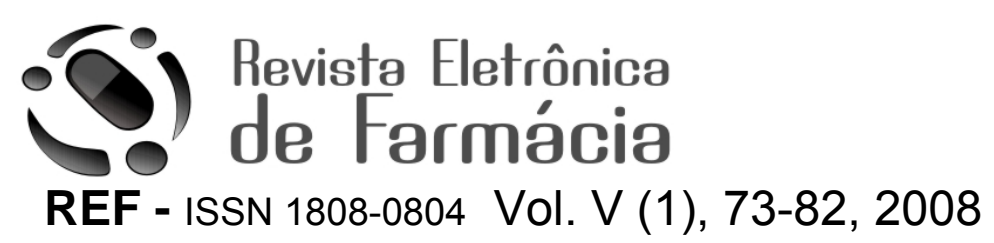

\title{
PIPER METHYSTICUM G. FORSTER (KAVA-KAVA): UMA ABORDAGEM GERAL
}

\author{
Piper methysticum G. Forster: (KAWA-KAWA): A general approach \\ Seilin Cardoso Justo $;^{1^{*}}$ Chana de Medeiros da Silva ${ }^{2,3}$ \\ ${ }^{1}$ Acadêmica do Curso de Farmácia, Universidade de Santa Cruz do Sul - Avenida Independência n 2293, 9685- \\ 900, Santa Cruz do Sul - RS - Brasil. \\ ${ }^{2}$ Departamento de Biologia e Farmácia da UNISC. \\ ${ }^{3}$ Professora da disciplina de Farmacognosia da UNISC.
}

*Autor para correspondência e-mail: seilinjusto@yahoo.com.br

Recebido em 12/07/2007 - Aceito em 21/06/2008

\begin{abstract}
RESUMO: O Piper methysticum G. Forster, conhecido popularmente como Kava-Kava, pertencente à família Piperaceae, é originário das ilhas do Oceano Pacífico. Há tempos, vem sendo utilizado mundialmente como alternativa ao uso dos ansiolíticos e sem orientação médica, o que pode constituir risco a saúde da população. Seu mecanismo de ação, devido à grande diversidade de atividades farmacológicas relatadas, não permite uma explicação simples, sendo que, diversos estudos são realizados na tentativa de elucidar esta questão. Atualmente, recebeu tarja vermelha com a frase "venda sob prescrição médica", isto devido aos casos de toxicidade hepática associados ao seu uso. Este trabalho, diante do exposto, e da carência de material literário sobre esta planta, tem o objetivo de realizar amplo levantamento bibliográfico sobre a espécie em questão, abordando seu histórico de uso, aspectos fitoquímicos, farmacológicos e toxicológicos.
\end{abstract}

PALAVRAS-CHAVE: Piper methysticum, Piperaceae, farmacologia, plantas medicinais.

ABSTRACT: The Piper methysticum G. Forster, known popularly as kawa-kawa, pertaining to the Piperaceae family, is originary of the Pacific Islands. There are times, has been used worldwide as an alternative to the use of anxiolytics and without medical advice, wich may constitute risk health of the population. Its mechanism of action, due to great diversity of pharmacological activities reported, does not allow a simple explanation, being that, diverse studies are carried through in the attempt to elucidate this question. Currently, received red target with the phrase "selling under medical prescription", this had to the cases of hepatic toxicity associates to its use. This work, ahead of the displayed one, and the lack of literary material on this plant, has the objective to carry through ample bibliographical survey on the species in question, being approached its description of use, phytochemical, pharmacological and toxicity aspects.

KEYWORDS: Piper methysticum, Piperaceae, pharmacology, medicinal plants.

\section{INTRODUÇÃO}

Desde os primórdios da humanidade, o homem busca nas plantas recursos terapêuticos para tratar suas enfermidades. Neste contexto, surgiram os medicamentos fitoterápicos, cuja variedade de espécies vegetais empregadas em sua produção, é reflexo direto do vasto conhecimento da população com relação ao uso e manejo das plantas medicinais (LORENZI \& MATOS, 2002; OLIVEIRA \& AKISUE, 2002; CORDEIRO et al., 2005; VEIGA JÚNIOR \& PINTO, 2005; RODRIGUES et al., 2006). Entretanto, a carência de estudos, principalmente na área toxicológica torna, infelizmente, o uso das plantas medicinais e dos medicamentos fitoterápicos, uma alternativa ainda duvidosa de se tratar, curar ou prevenir doenças (MORAES et al., 2005).

Apesar dos avanços ocorridos na indústria de fármacos sintéticos, os fitoterápicos não perderam seu lugar na terapêutica (CORDEIRO et al., 2005). Isso se deve, em parte, ao alto custo dos medicamentos industrializados, a decepção com tratamentos convencionais, a efeitos indesejáveis ocorridos pelo uso incorreto ou indevido dos medicamentos sintéticos e, especialmente, porque para muitos, o termo natural significa "ausência de produtos 
Justo, S. C. et al./Revista Eletrônica de Farmácia Vol 5(1), 73-82, 2008.

químicos", que são aqueles que podem causar algum malefício ou representam perigo (RATES, 2001; YUNES et al., 2001; MENGUE et al., 2001 citado por OLIVEIRA \& GONÇALVES, 2006), sendo que, a falta de conhecimento por parte da população sobre possíveis efeitos secundários e tóxicos de diversas plantas pode levar a graves conseqüências (NAVARRO MOLL, 2000 citado por OLIVEIRA \& GONÇALVES, 2006).

Dentre a ampla variedade de fitoterápicos existentes, destaca-se o Piper methysticum G. Forster, popularmente conhecido como Kava-kava, que entre os anos de 1999 a 2002, esteve entre os 10 medicamentos fitoterápicos mais vendidos no Brasil, sendo utilizado, principalmente, para o tratamento de ansiedade e insônia e como alternativa ao uso dos benzodiazepínicos (CORDEIRO et al., 2005; TUROLLA \& NASCIMENTO, 2006). No mercado farmacêutico brasileiro, é conhecido como Ansiopax ${ }^{\circledR}$, Laitan $®$, Kavasedon $\AA$, entre outros e, recentemente, recebeu tarja vermelha com a frase "venda sob prescrição médica", devido ao fato de ser largamente utilizado sem orientação médica ou farmacêutica e, principalmente, devido aos vários relatos de hepatotoxicidade associados ao seu uso (ARRUDA et al., 2005; TUROLLA \& NASCIMENTO, 2006).

\section{ASPECTOS GERAIS}

A espécie Piper methysticum G. Forster pertence à família Piperaceae, cujo principal gênero - Piper - tem ampla distribuição nos dois hemisférios, tanto em regiões tropicais como em subtropicais, sendo muito conhecido por suas propriedades medicinais, ornamentais, alimentícia e industrial (NAKAMURA et al., 2006).

Popularmente, a espécie é conhecida por pimenta-intoxicante, kava, kava-kava, raiz-kava, pimenta-kava entre outros (CORDEIRO et al., 2005).

É um arbusto dióico, ereto, com dois a três metros de altura, folhas grandes e rígidas profundamente cortadas na base (Figura 1A). Possue de 9 a 13 nervuras principais, sendo menos proeminentes na face interior; estípulas presentes e grandes (ARRUDA et al., 2005). Apresenta inúmeras flores pequenas, que se arranjam em cachos tipo espigas, com 3 a 9 centímetros de comprimento (SCHÜLZ et al., 2002; ARRUDA et al., 2005).
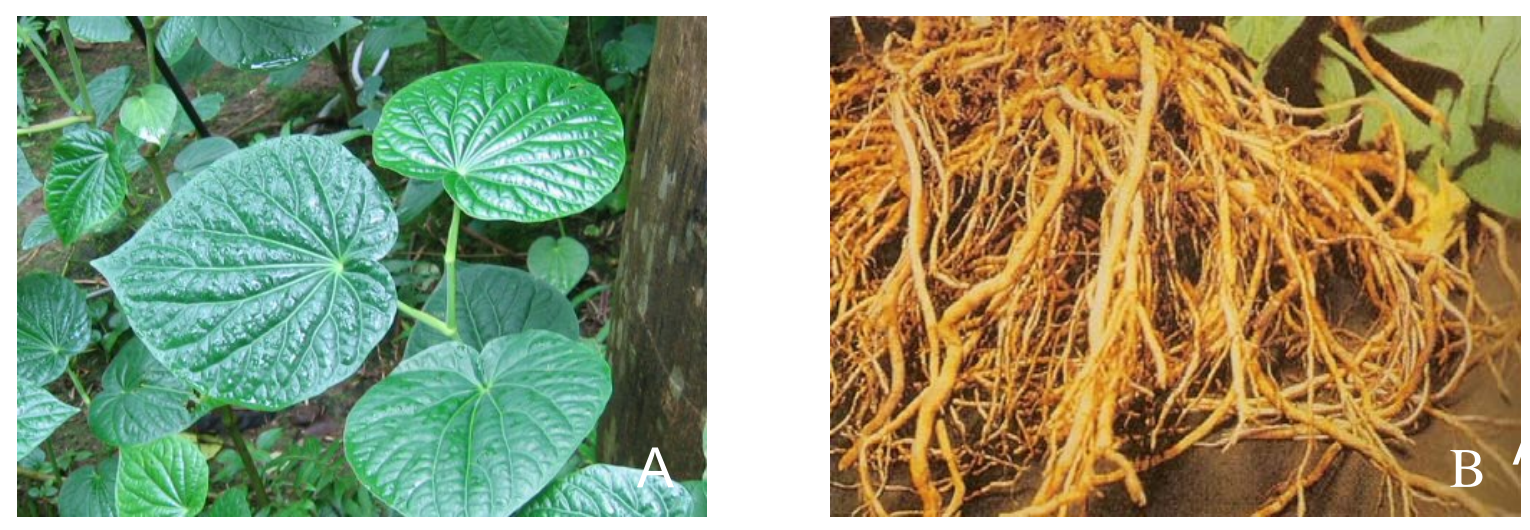

Figura 1: Aspectos de P. methysticum.. A - Detalhe das folhas; B - Rizoma. Fonte: SCHÜLZ et al., 2002.

O caule é subterrâneo do tipo rizoma (Figura 1B), podendo pesar até $10 \mathrm{~kg}$, ramificado, suculento, com várias raízes, cor negro-acinzentado por fora e esbranquiçado no interior. A parte central do rizoma é bastante porosa com feixes lenhosos e finos que são torcidos de forma irregular e separados por raios medulares, dando origem a malhas sob a casca (ARRUDA et al., 2005).

A droga vegetal é o rizoma seco, que possue odor fracamente aromático e sabor levemente amargo. Mastigar o rizoma de kava provoca dormência na língua e salivação. Atualmente, esta planta não cresce mais naturalmente, sendo que seu cultivo se dá para fins comerciais (SCHÜLZ et al., 2002). A kava é originária das ilhas do Oceano Pacífico, principalmente na Polinésia Central, com exceção de Nova Zelândia, Nova Caledônia e grande parte das ilhas Salomão (CAIRNEY et al., 2003; WU et al., 2004; ZOU et al., 2004). Inicialmente era usada apenas em ritos religiosos, porém nos anos 80 , foi introduzida nas comunidades aborígines da Austrália, onde se tornou uma droga de abuso (SHING, 1992).

A bebida de kava é feita a partir da trituração do rizoma seco, maceração do mesmo em água fria, seguido de percolação do líquido. Os extratos são preparados pela extração da droga vegetal com uma mistura de etanol e água, quando se deseja extratos com aproximadamente $30 \%$ de princípio ativo. Usa-se mistura de acetona e água para extratos mais concentrados, contendo até $70 \%$ de princípio ativo (SCHÜLZ et al., 2002).

\section{CONSTITUÍNTES QUÍMICOS}

Esta espécie apresenta em sua constituição química diversas substâncias, como taninos (CUNHA et al., 2003), ácido benzóico, ácido cinâmico, açúcares, bornil-cinamato, estigmasterol, flavocavaínas, mucilagens, 
Justo, S. C. et al./Revista Eletrônica de Farmácia Vol 5(1), 73-82, 2008.

pironas, tetrahidroiangoninas e alguns sais minerais, principalmente o potássio. Porém, os principais constituintes da Kava, responsáveis por suas atividades farmacológicas são as a-pironas, denominadas cavalactonas ou cavapironas (Figura 2) (CORDEIRO et al., 2005).

Foram identificadas 18 cavalactonas no rizoma da espécie, sendo que destas, as seis que apresentam maior importância farmacológica são: iangonina, metisticina, cavaína, desmetoxiangonina, dihidrocavaína e dihidrometisticina (Tabela 1) (Simões, 2001citado por PINTO et al., 2005).

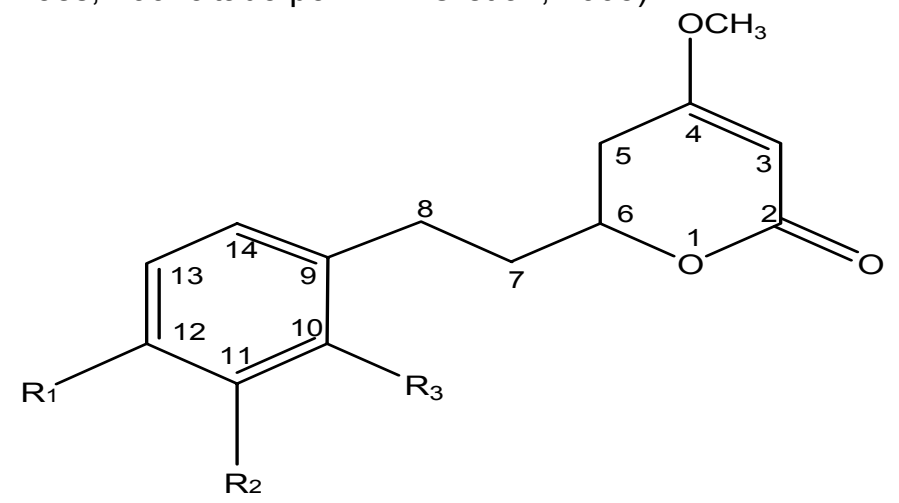

Figura 2: Estrutura geral das cavalactonas presentes em P. methysticum. Fonte: ARRUDA et al., 2005.

Tabela 1: Principais cavapironas presentes em P. methysticum.

\begin{tabular}{|c|c|c|}
\hline CAVAPIRONA & CARBONO & GRUPO \\
\hline Dihidrocavaína & 6 & 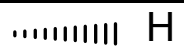 \\
\hline Desmetoxiangonina & $\begin{array}{l}5-6 \\
7-8 \\
\end{array}$ & $\overline{\overline{\overline{\overline{ }}}}$ \\
\hline Cavaína & $\begin{array}{c}6 \\
7-8\end{array}$ & 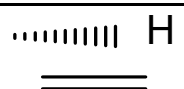 \\
\hline Dihidrometisticina & $\begin{array}{c}6 \\
11-12\end{array}$ & III $\mathrm{H}$ \\
\hline langonina & $\begin{array}{c}5-6 \\
7-8 \\
12\end{array}$ & $\mathrm{CH}_{3} \mathrm{O}$ \\
\hline Metisticina & $\begin{array}{c}6 \\
7-8 \\
11-12\end{array}$ & ‥1!n!lı H \\
\hline
\end{tabular}

Fonte: a autora, adaptado de WU et al., 2004.

A concentração destes constituintes pode variar de 3 a $20 \%$ de planta para planta (Tabela 2), conforme os procedimentos de colheita, secagem, armazenamento e processamento (PINTO et al., 2005), porém é na resina onde está presente a maior parte dessas cavapironas (KELEDJIAN et al., 1998), sendo que a planta seca deve apresentar no mínimo 3,5\% de cavalactonas, calculadas como cavaína. Estas substâncias são poucos solúveis em água, apresentam tempo de meia-vida que pode variar de 90 minutos a várias horas no plasma e biodisponibilidade bastante variável (SCHÜLZ et al., 2002).

Tabela 2: Concentração das cavalactonas presentes no rizoma de $P$. methysticum.

\begin{tabular}{c|c}
\hline CAVALACTONAS & CONCENTRAÇÃO MÉDIA (\%) \\
\hline Cavaína & $1,0-2,0$ \\
Dihidrocavaína & $0,6-1,0$ \\
\hline
\end{tabular}


Justo, S. C. et al./Revista Eletrônica de Farmácia Vol 5(1), 73-82, 2008.

\begin{tabular}{c|c}
\hline Metisticina & $1,2-2,0$ \\
Dihidrometisticina & $0,5-0,8$ \\
langonina & $1,0-1,7$ \\
Desmetoxiangonina & $0,6-1,0$ \\
\hline
\end{tabular}

Fonte: SCHÜLZ et al., 2002.

\section{EMPREGO TERAPÊUTICO}

Segundo Singh (1992) e Sweetman (2002), popularmente a Kava é usada para tratar gonorréia, dor menstrual, tuberculose e problemas respiratórios. Também foi referida sua utilização como analgésico, diurético e relaxante do músculo liso. Alguns moradores da região do pacífico a utilizam como enxaguatório bucal, para tratar úlceras orais e dor de dente, contra veneno de cobra e outros animais peçonhentos e, na homeopatia, é usada nos estados de excitação, exaustão e gastrite. Conforme Mesquita e colaboradores (2005), na Europa, produtos contendo extratos hidroalcoólicos, o pó ou até mesmo as raízes de $P$. methysticum são muito comercializados para o tratamento de ansiedade e insônia.

A Kava, em preparações não-fermentadas, era usada no tratamento da dor, nevralgia, convulsões e inquietude (SIMÕES et al., 1999 citado por ARRUDA et al., 2005). Sua utilização também foi relatada em casos de perturbações do climatério, vaginites (uso tópico), anestésico local, prostatites, cistites e inflamações osteoarticulares (CUNHA et al., 2003), resfriados, problemas intestinais, abscessos, cicatrização de feridas (PIERCE, 1999 citado por CORDEIRO et al., 2005), fraqueza física, perda de peso e dificuldades de lactação (BLUMENTHAL, 1998 apud ARRUDA et al., 2005).

Segundo os nativos, os efeitos provocados pela bebida de Kava melhoravam o convívio social, e em casos de consumo excessivo poderia induzir ao sono em 30 minutos. Entretanto, muitas destas aplicações são apenas folclóricas, mas que acabaram por impulsionar diversas investigações científicas (GARY PISCOPO, 1997).

\section{ATIVIDADE FARMACOLÓGICA}

Entre as indicações terapêuticas para o uso do $P$. methysticum, está a sua utilização contra tensão, agitação e ansiedade nervosa (SCHÜLZ et al., 2002). Isto porque o extrato de kava afeta o sistema nervoso central (SNC) proporcionando sensação de prazer e amenizando as sensações de medo (CAÑIGUERAL \& VILLA, 1998). Perifericamente, age como potente anestésico local, exercendo também efeito protetor contra envenenamento por estricnina, sendo superior a todos os antagonistas não-narcóticos conhecidos (JAMIESON et al., 1989; BACKHAUSS \& KRIEGLSTEIN, 1992; SCHÜLZ et al., 2002).

As cavalactonas também apresentam a capacidade de inibir diversas isoformas do citocromo P450 (CYP450), sendo elas: CYP1A2, CYP2C9; CYP2C19; CYP2D6, CYP3A4; CYP4A9 e CYP4A9/11. Esta propriedade é fonte de inúmeras interações, principalmente farmacocinéticas, com outras drogas, pois diminui a metabolização destas pelas enzimas inibidas do complexo CYP450, podendo induzir a toxicidade (UNGER et al., 2002; ANKE \& RAMZAN, 2004; ZOU et al., 2004).

Outra atividade atribuída aos componentes da Kava é a analgesia. A dihidroxicavaína e a dihidrometisticina em concentrações de $120 \mathrm{mg}$ por quilo de peso corporal são equivalente à ingestão de $200 \mathrm{mg}$ de ácido acetil salicílico (AAS) por quilo de peso corporal (WU et al., 2004). Backhauss e Krieglstein (1992) também defendem a atividade neuroprotetota da metisticina e da dihidrometisticina, que diminuíram a área cerebral atingida por danos provenientes de isquemia em ratos. As demais cavapironas não demonstraram possuir esta ação.

Gleitz e colaboradores (1997) injetaram cavaína em ratos 5 minutos antes de injetarem ácido araquidônico, e perceberam uma diminuição dose-dependente da agregação plaquetária, sugerindo que a atividade sobre a enzima ciclooxigenase-1 (COX-1) seja o alvo principal das cavalactonas. Todavia, a kava não age seletivamente, pois é também, capaz de inibir a enzima COX-2, com potência comparada a de $2,5 \mu \mathrm{g} / \mathrm{mL}$ do fármaco naproxefeno.

Contudo, é a propriedade ansiolítica desta planta o principal alvo dos estudos científicos. O efeito de uma dose diária equivalente a $210 \mathrm{mg}$ de cavapirona foi comparado com o efeito de $15 \mathrm{mg} / \mathrm{dia}$ de oxazepam ou 9 $\mathrm{mg} /$ dia de bromazepam em um estudo duplo-cego de seis meses de duração (WOELK et al., 1993 apud SCHÜLZ et al., 2002). A ação ansiolítica da Kava não apresenta os efeitos adversos dos benzodiazepínicos como prejuízo das funções cognitivas, sonolência, redução da coordenação motora e dependência (MUNTE et al., 1993; TYLER \& ROBBERS, 2000 citado por PINTO et al., 2005).

Ainda destacando os efeitos da Kava sobre o SNC, tem-se a atividade anticonvulsivante, que pode estar associada à ação antagonista das cavalactonas, em especial da cavaína, sobre canais de sódio dependentes de voltagem (GLEITZ et al., 1997) e de cálcio tipo L (GRUNZE et al., 1997; SCHIRRMACHER et al., 1999; GARRETT et al., 2003). 
Justo, S. C. et al./Revista Eletrônica de Farmácia Vol 5(1), 73-82, 2008.

A baixa incidência de câncer de estômago, pulmão e próstata nos habitantes da ilha de Fijian (pertencente às ilhas do Pacífico), comparado aos moradores de outras ilhas como Polinésia, Micronésia e Nova Caledônia despertou curiosidade nos pesquisadores. Estes perceberam que o povo de Fijian tinha o hábito de beber Kava na busca de sua atividade analgésica, costume que não ocorria com os moradores das outras ilhas. Por esse motivo, passaram a estudar a constituição química do Kava e acabaram por identificar uma nova cavapirona, a 7,8 epoxiangonina (Figura 3), capaz de diminuir significativamente a liberação do fator $\alpha$ de necrose tumoral (FNT- $\alpha$ ), um importante marcador de tumores (HASHIMOTO et al., 2003).<smiles>COc1ccc(C2OC2c2cc(OC)cc(=O)o2)cc1</smiles>

Figura 3: Estrutura química da cavalactona 7,8 epoxiangonina.Fonte: HASHIMOTO et al., 2003.

\section{MECANISMO DE AÇÃO}

O mecanismo de ação das cavalactonas ainda não está bem esclarecido, existindo dados contraditórios sobre a interação destas, principalmente da dihidrocavaína, com o receptor do ácido gama-aminobutírico (GABA), sendo que um trabalho remete ao aumento dos sítios de ligação (modulação) nestes receptores, ocorrendo uma redução significativa nas descargas neuronais (YUAN et al., 2002) e outro relata ausência de atividade nestes sítios e também nos sítios de ligação dos benzodiazepínicos (DAVIES et al.,1992).

Devido à característica extremamente lipofílica das cavapironas, é possível que estas atuem sobre a fluidez da membrana lipídica celular, alterando a conformação de vários receptores, agindo de maneira não seletiva (CAIRNEY et al., 2003).

Estudos farmacológicos em animais indicaram ações sedativas, relacionadas com a ativação da transmissão dopaminérgica e serotoninérgica na região mesolímbica, o que estaria associado com a redução da excitabilidade emocional e alterações comportamentais (SCHENKEL et al., 2001).

Já outro grupo de autores afirma que as cavapironas interagem sim com receptores GABA-A através de um efeito alostérico e que também inibem canais de sódio dependentes de voltagem e atacam receptores $\mathrm{H} 3$, mas não alteram os níveis dos neurotransmissores dopamina e serotonina (KRETZSCHMAR, 1995 apud SCHÜLZ et al., 2002).

A inibição reversível da enzima monoamino oxidase B (MAO-B) tanto pelo extrato de Kava como pelas cavalactonas isoladas pode ser um mecanismo importante para sua ação psicotrópica, sendo que as diferenças estruturais das cavalactonas resultaram em diferentes potenciais de inibição, onde se obteve: desmetoxiangonina > metisticina > iangonina > dihidrometisticina > dihidrocavaína > cavaína (UEBELHACK et al., 1998).

\section{DOSAGEM E CONTRA-INDICAÇÕES}

A dosagem da Kava é medida em cavalactonas, sendo que por dia a dose deve estar entre 60-120 mg (ARRUDA et al., 2005).

A Kava pode potencializar os efeitos deletérios no fígado quando associado com fármacos potencialmente hepatotóxicos, como antidepressivos tricíclicos, inibidores da MAO e inibidores de apetite. Assim, pessoas com doença hepática devem evitar seu uso (CORDEIRO et al., 2005).

Pessoas com hipersensibilidade a Kava, portadores de Doença de Parkinson, pelo risco de ocorrerem aumento dos sintomas extra-piramidais, de depressão endógena ou psicótica, onde pode ocorrer agravamento da doença, bem como crianças e mulheres no período gestacional, por não haverem estudos de segurança nestes períodos devem evitar o uso de preparações contendo Kava (CAÑIGUERAL \& VILA, 1998).

\section{EFEITOS ADVERSOS E TOXICIDADE}

Segundo Cunha e colaboradores (2003), em doses terapêuticas nenhum efeito secundário tem sido referido. Porém, há relatos que a Kava pode causar reações alérgicas, pigmentação da pele (LITT, 2001 citado por PINTO et al., 2005), fadiga matinal no início do tratamento, movimentos involuntários estereotipados, prejuízos na deglutição e respiração, contrações involuntárias arrítmicas e contínuas das extremidades (ROBBERS et al., 
Justo, S. C. et al./Revista Eletrônica de Farmácia Vol 5(1), 73-82, 2008.

1996 apud PINTO et al., 2005), desconforto gastrintestinal, cefaléias, tonturas (SCHÜLZ et al., 2002), perda do tônus uterino (PIERCE, 1999 citado por CORDEIRO et al., 2005), dilatação das pupilas e distúrbios do equilíbrio (ARRUDA et al., 2005).

A ingestão da bebida de Kava em concentrações acima de 300 gramas por semana por alguns meses pode causar dermatopatias que desaparecem após a interrupção do tratamento (ROBBERS et al., 1996 apud PINTO et al., 2005). O uso prolongado de Kava também tem relações com saúde debilitada, incluindo baixo peso do usuário, proteínas plasmáticas, uréia e bilirrubina em níveis reduzidos, faces inchadas, número aumentado de hemácias e diminuído de plaquetas e linfócitos, além de hipertensão pulmonar (CAÑIGUERAL \& VILA, 1998).

Também há relatos de que o consumo excessivo de kava pode resultar em má nutrição, perda de peso e disfunção hepática e renal. Porém, não se sabe se esses efeitos foram produzidos somente pelo uso da Kava ou se podem ser potencializados pelo álcool (TUROLLA \& NASCIMENTO, 2006). Em exames in vitro, foi demonstrada positividade mutagênica e negatividade teratogênica (KRETZSCHMAR et al., 1999 apud SCHÜLZ et al., 2002).

Na Alemanha e na Suíça, no ano de 2001, ocorreram 25 casos graves de hepatotoxicidade. Destes, 6 foram de insuficiência hepática grave, com uma morte. Casos de cirrose hepática e um transplante de fígado, associada ao uso de kava, também foram relatados, tornando seu uso proibido nesses países. No Canadá, quatro casos de problemas hepáticos ocorreram e também foram associados ao uso de produtos contendo Kava (BOON \& WONG, 2003).

A Kava pode exacerbar problemas hepáticos, havendo relatos de hepatite aguda com necrose hepatocelular severa com necessidade de transplante de fígado após a utilização de doses terapêuticas do extrato de Kava (PIERCE, 1999 citado por CORDEIRO et al., 2005). Porém, alguns autores fazem apontamentos de que a maioria dos casos de insuficiência hepática podem não ter relação com o uso da planta e informam que as respostas quanto aos casos de hepatotoxicidade são insatisfatórias (ANKE \& RAMZAN, 2004).

\section{INTERAÇÕES FARMACOLÓGICAS}

Existem algumas interações farmacológicas da Kava com certos medicamentos, principalmente derivados de outras plantas medicinais, como o hipérico e a valeriana (Tabela 3) (ARRUDA et al., 2005).

Tabela 3: Principais interações farmacológicas descritas para P. methysticum.

Interações com plantas sedativas

Interações com fármacos
- Cálamo, calêndula, aipo, ênula, valeriana, sassafrás, camomila alemã, erva-dos-gatos. O uso concomitante destas com Kava pode causar sinergia dos efeitos terapêuticos e adversos da Kava.

- O uso concomitante de Kava com depressores do SNC pode acentuar os efeitos depressores destes; existe relato de coma devido à associação com alprazolam.

- Ocorre diminuição do efeito da levodopa devido, provavelmente, ao antagonismo da dopamina.

- Os inibidores da MAO associados à Kava causam inibição excessiva da enzima, aumentando a toxicidade da Kava.

- A associação da Kava com digitálicos provoca antagonismo plaquetário.

Interações com alimentos

- O uso concomitante com o álcool pode acentuar os efeitos hepatotóxicos da planta.

Fonte: a autora, adaptado de ARRUDA et al., 2005; CORDEIRO et al., 2005.

Interações entre a Kava e o álcool sempre foram mencionadas. Para elucidar esta incógnita, realizaram-se testes para descobrir se a kava inibe a enzima álcool desidrogenase, responsável pela conversão do etanol em acetaldeído. Para tanto, testaram-se três concentrações diferentes de três cavalactonas (cavaína, metisticina e iangonina) e não foi percebida diminuição da metabolização do etanol. Isto implica que pelo menos através deste mecanismo, é improvável que a Kava interaja com o álcool (ANKE et al., 2006).

\section{LEGISLAÇÃO}


Justo, S. C. et al./Revista Eletrônica de Farmácia Vol 5(1), 73-82, 2008.

A legislação para medicamentos fitoterápicos vem sofrendo modificações nos últimos anos. A Agência Nacional de Vigilância Sanitária (ANVISA), em busca da garantia da qualidade destes medicamentos, vem elaborando normas para a regulamentação destes, desde a Portaria n. 6 de 1995, que estabeleceu datas para que as indústrias apresentassem resultados de eficácia e segurança dos fitoterápicos, passando pela Resolução RDC n. 17 de 2000 (BRASIL, 2000) até chegar à resolução da diretoria colegiada (RDC) n.48 de 2004 (TUROLLA \& NASCIMENTO, 2006).

Com relação ao P. methysticum, a RDC n. 48 (BRASIL, 2004a), juntamente com a RE n. 89 de 2004 (BRASIL, 2004b) facilitam seu registro como medicamento fitoterápico por incluí-lo na Lista de Registro Simplificado de Fitoterápicos, que não exige a validação das indicações terapêuticas e a segurança de uso, desde que sejam obedecidas condições definidas. Com relação ao Kava-Kava, devem ser respeitadas integralmente as seguintes especificações:

- Parte utilizada: rizoma;

- Marcador: cavapironas;

- Formas de uso: extratos ou tinturas;

- Indicações: ansiedade, agitação, insônia e tensão nervosa;

- Dose diária: 60 a 120 mg de cavapironas;

- Via de administração: oral

- Restrição de uso: venda sob prescrição médica; utilizar no máximo por dois meses (BRASIL, 2004b).

Outras formas farmacêuticas poderão ser formuladas, porém, sempre na mesma via de administração e desde que estudos de bioequivalência sejam apresentados (ARRUDA et al., 2005).

Os 25 casos de hepatotoxicidade já relatados anteriormente, influenciaram a ANVISA, conforme a Resolução - RE n. 356 de 28 de fevereiro de 2002, a incluir uma tarja vermelha com a frase "venda sob prescrição médica", nos produtos a base de Kava-Kava. Outro ponto para a adoção dessa medida é o fato de muitos brasileiros considerarem produtos a base de plantas totalmente inócuos, o que não condiz com a realidade (BRASIL, 2002).

\section{CONSIDERAÇÕES FINAIS}

A utilização de plantas como fonte de medicamentos remonta à idade antiga e vem evoluindo ao longo dos anos, sendo que, atualmente, a utilização destas está em contínua e acelerada expansão em nível mundial.

O emprego de matérias-prima oriundas de plantas para produção de fitoterápicos tem sido no Brasil e em diversos países, o suporte da indústria farmacêutica, principalmente para as de pequeno e médio porte. Porém, apesar da grande utilização destes medicamentos e do grande número de espécies vegetais nativas consideradas medicinais, poucos são os estudos que visam à comprovação das propriedades terapêuticas, qualidade, segurança e eficácia de uso, o que acaba por contribuir para certo descrédito que rodeia os fitoterápicos e acarretando à população prejuízos diversos como possíveis efeitos colaterais até a ausência dos efeitos benéficos pretendidos com o seu uso. Tais problemas, no entanto, envolvem majoritariamente casos de adulteração e/ou confusão já bastante conhecidos.

Fitoterápicos a base de $P$. methysticum são amplamente utilizados em todo o mundo, principalmente para o tratamento da ansiedade e na maioria das vezes sem orientação médica, constituindo risco para a saúde pública, devido aos vários relatos de hepatotoxicidade e, principalmente, à falta de orientação e controle de seu uso. Com isso, os profissionais da saúde devem estar aptos a orientar seus pacientes sobre o uso indiscriminado, não só da kava, como também dos fitoterápicos e ervas medicinais em geral, devido ao alto poder de interações e reações adversas que estes produtos podem apresentar.

$\mathrm{E}$, apesar de todos os avanços já conquistados, a regulamentação dos fitoterápicos permanece como uma questão em aberto. Enquanto toda a legislação para os medicamentos sintéticos encontra-se bem estabelecida, os medicamentos fitoterápicos ainda carecem de maior esforço regulatório.

\section{REFERÊNCIAS BIBLIOGRÁFICAS}

ANKE, J. RAMZAN, I. Pharmacokinet and pharmacodynamic drug interactions with Kava (Piper methysticum Forst f.). Journal of Ethnopharmacology, v. 93, p. 153-160, ago. 2004.

FU, S.; RAMZAN, I. Kavalactonas fail to inhibit alcohol dehydrogenase in vitro. Phytomedice: International Journal or Phytotherapy \& Phytopharmacology, v.13, n. 3, p. 192-196, fev.2006.

ARRUDA, A. M. de et al. Piper methysticum L. (Kava-Kava): Histórico do uso e aspectos taxonômicos, farmacológicos e toxicológicos. Revista em Ciências da Saúde, n. 2, p. 59-68, 2005. 
Justo, S. C. et al./Revista Eletrônica de Farmácia Vol 5(1), 73-82, 2008.

BACKHAUSS, C. KRIEGLSTEIN, J. Extract of Kava (Piper methysticum) and its methysticin constituents protect brain tissue against ischemic damage in rodents. European Journal Pharmacology, v. 14, n. 215, p. 265-269, mai. 1992.

BOON, H. S.; WONG, A. H. C. kava: a test case for Canada's new to natural health products. Canadian Medical association Journal, v. 169, n.11, p. 1163, nov. 2003.

BRASIL (2004a). Agência Nacional de Vigilância Sanitária. Legislação. Sistema de Legislação em Vigilância Sanitária (VISALEIS). Resolução RDC n. 48 de 16 de março de 2004 . Disponível: http://elegis.bvs.br/leisref/public/search.php [capturado em 24 mar. 2007].

(2004b). Resolução - RE n. 89 de 16 de março de 2004. Diário Oficial da União; Poder Executivo, Brasília, $\overline{\mathrm{DF}}, 18$ mar. 2004. Disponível: http://e-legis.anvisa.gov.br/leisr. php?id=102417\&word= [capturado em: 24 mar.2007].

(2002). Agência Nacional de Vigilância Sanitária. Legislação. Sistema de Legislação em Vigilância Sanitária (VISALEIS). Resolução - RE n. 356 de 28 de fevereiro de 2002. Disponível: http: elevis.bvs.br/leisref/public/search.php [capturado em 24 mar. 2007].

(2000). Agência Nacional de Vigilância Sanitária. Sistema de Legislação em Vigilância Sanitária (VISALEIS). Resolução - RDC n. 17 de 24 de fevereiro de 2000. Disponível: http://www.anvisa.gov.br/medicamentos/legis/resol.htm [capturado em: 24 mar. 2007].

CAÑIGUERAL, S.; VILA, R. Fitoterapia: Concepto y Limites, Fuentes de Información. In Fitoterapia (Vandemécum de Prescripción). España: Masson \& Cie, 1998.

CAIRNEY, S. et al. Saccade and Cognitive Function in Chronic Kava Users. Neuropsychopharmacology, n. 28, p.389-396, 2003.

CORDEIRO, C. H. G.; CHUNG, M. C.; SACRAMENTO, L. V. S. Interações medicamentosas de fitoterápicos e fármacos: Hypericum perforatum e Piper methysticum. Revista Brasileira de Farmacognosia, v.15, n.3, p.272-278, jul./set.2005.

CUNHA, A. P.; SILVA, A.P.; ROQUE, O. R. Plantas e produtos vegetais em fitoterapia. Lisboa: Fundação Calouste Gulbenkian, 2003.

DAVIES, L. P. et al. Kava pyrones and resin: studies on GABA-A, GABA-B and benzodiazepine binding sites in rodent brain. Pharmacology and Toxicology, v. 71, n. 2, p. 120-126, ago. 1992.

GARRET, K. M. et al. Extracts of Kava (Piper methysticum) induce acute anxiolytic-like behavioral changes in mice. Psychopharmacology, n. 170, p.33-41, jul.2003.

GARY PSCOPO, N.D. Kava-Kava: gift of the island. Alternative Medicine Review, v.2, n.5. p. 355-364, 1997.

GLEITZ, J.; BEILE, A.; PETERS, T. (+/-) - Kavain inhibits veratridine-activated voltage-dependent Na $(+)-$ channels in synaptosomes prepared from rat cerebral cortex. Neuropharmacology, v. 34, n. 9, p. 1133-1138, set. 1997.

GRUNZE, $H$. et al. Effects of kawain and dihydromethysticin on field potential changes in the hippocampus. Neuropsychopharmacology Biol Psychiatry, v. 21, n. 4, p.697-706, maio de1997.

HASHIMOTO, T. et al. Isolation and synthesis of TNF- $\alpha$ release inhibitors from Fijian Kawa (Piper methysticum). Phytomedice, n.10, v. 4, p. 309-317, maio de 2003.

JAMIESON, D.D. et al. Comparison of the central nervous system activity of the aqueous and lipid extract of Kava (Piper methysticum). Archives internationales de pharmacodinamie et de therapie, n. 301, p. 66-80, set. /out. 1989.

KELEDJIAN, J. et al. Uptake intomouse brain of four compounds present in the Psychoactive Beverage Kava. Journal of Pharmaceutical Sciences, v. 77, n. 12, p. 1003-1006, 1998. 
Justo, S. C. et al./Revista Eletrônica de Farmácia Vol 5(1), 73-82, 2008.

LORENZI, H.; MATOS, F.J.A. Plantas medicinais no Brasil: nativas e exóticas cultivadas. Nova Odessa: Instituto Plantarum, 2002.

MESQUITA, J. M. O. et al. Estudo comparativo dos óleos voláteis de algumas espécies de Piperaceae. Revista Brasileira de Farmacognosia, v.15, n.1, p. 6-12, jan. / mar. 2005.

MORAIS, I.C. et al. Levantamento sobre plantas medicinais comercializadas em Goiânia; abordagem popular (raizeiros) e abordagem científica (levantamento bibliográfico). Revista Eletrônica de Farmácia, v. 2, n.1, p. 13-16, 2005.

MUNTE, T. F. et al. Effects of oxazepam and an extract of Kava roots (Piper methysticum) on event-related potentials in a word recognition task. Neuropharmacology, v. 27, n. 1, p. 46-53, 1993.

NAKAMURA, C. V. et al. Atividade antileishmania do extrato hidroalcoólico e de frações obtidas de folhas de Piper regnellii (Miq) C. DC. Var. pallescens (C. DC.) Yuncck. Revista Brasileira de Farmacognosia, v.16, n.1, p. 61-66, jan./ mar. 2006.

OLIVEIRA, F.; AKISUE, G. Fundamentos de Farmacobotânica. São Paulo; Editora Atheneu, 2002.

OLIVEIRA, F.Q.; GONÇALVES, L.A. Conhecimento sobre plantas medicinais e fitoterápicos e potencial de toxicidade por usuários de Belo Horizonte, Minas Gerais. Revista Eletrônica de farmácia, v. 3, n.2, p. 36-41, 2006.

PINTO, V. M. et al. Avaliação do uso de Piper methysticum quanto ao desenvolvimento de hepatotoxicidade em ratos Wistar. Veterinária em Foco, v. 3, n. 1, p. 21-26, mai. /dez. 2005.

RATES, S. M. K. Promoção do uso racional de fitoterápicos: uma abordagem no ensino de Farmacognosia. Revista Brasileira de Farmacognosia, v. 11, n. 2, p. 57-59, 2001.

RODRIGUES, A. G.; SANTOS, M. G.; AMARAL, A. N. In: BRASIL, Ministério da Saúde. A fitoterapia no SUS e o programa de Pesquisas de Plantas Medicinais da Central de Medicamentos. 1 ed. Brasília-DF: Ed. do MS, 2006, p.9-26.

SCHENKEL, L. C.; GOSMANN, G.; PETROVICK P. R. Produtos de origem vegetal e o desenvolvimento de medicamentos. In: SIMÕES, C. M. O. et al. Farmacognosia: da planta ao medicamento. 3 ed. Porto Alegre/Florianópolis: Ed. da UFRGS/ Ed. da UFSC, 2001, p. 301-330.

SCHIRRMACHER, K. et al. Effects of (+/-) -kavain on voltage-activade inward currents of dorsal root ganglion cells from neonatal rats. Neuropsychopharmacol, p. 171-176, 1999.

SCHÜLZ, V.; HANSEL, R.; TYLER, V. E. Fitoterapia Racional - Um guia de fitoterapia para as ciências da saúde. $4^{\circ}$ ed. Barueri: Manole, 2002.

SINGH, Y. N. Kava: an overview. Journal of Ethnopharmacology, n. 37, p. 13-45, 1992.

SWEETMAN, N. Martindale - The complete drug reference. 33 ed. London: Pharmaceutical Press, 2002.

TUROLLA, M. S.; NASCIMENTO, E. S. Informações toxicológicas de alguns fitoterápicos utilizados no Brasil. Revista Brasileira de Ciências Farmacêuticas, v. 42, n. 2, p. 289-306, abr./jun.2006.

UEBELHACK, R., FRANKE, L., SCHEWE, H. J. Inhibition of platelet MAO-B by Kava pyrone-enriched extract from Piper methysticum Forster (Kava-kava). Pharmacopsycheatry, v. 31, n. 5, p. 187-192, set. 1998.

UNGER, M. et al. Inhibition of Cytochrome P4503A4 by extracts and kavalactones of Piper methysticum (kavaKava). Planta Médica, n. 68, p. 1055-1058, 2002.

VEIGA JÚNIOR, V. F.; PINTO, A.C. Plantas medicinais: cura segura? Química Nova, v.28, n.3, p. 519-528, 2005. 
Justo, S. C. et al./Revista Eletrônica de Farmácia Vol 5(1), 73-82, 2008.

YUAN, C. S. et al. Kavalactones and Dihidrokavain Modulate GABAergic Activity in a Rat Gastric-Brainstem Preparation. Planta Médica, v. 68, p. 1092-1096, 2002.

YUNES, R. A.; PEDROSA, R. C.; CECHINEL FILHO, V. Fármacos e fitoterápicos: A necessidade do desenvolvimento da indústria de fitoterápicos fitofármacos no Brasil. Química Nova, v. 24, n. 1, p. 147-152, 2001.

WU, D. et al. Cyclooxygenase enzyme inhibitory compounds with antioxidant activites from Piper methysticum (Kava Kava) roots. Phytomedice, v. 9, n.1, p. 41-47, jan. 2004.

ZOU, L. et al. Effects of Kava (kava-kava, 'Awa, yangona, Piper methysticum) on c-DNA- expressed cytochrome P450 enzymes and human cryopreserved hepatocytes. Phytomedicine, v.11, n. 4, p. 285-294, abr. 2004. 